\title{
ANÁLISIS DISTRIBUTIVO UTILIZANDO INFORMACIÓN SATELITAL. EL CASO DE ARGENTINA $^{\circ}$
}

\author{
DISTRIBUTIVE ANALYSIS USING SATELLITE DATA. THE CASE \\ OF ARGENTINA \\ Matías Ciaschi
}

enviado: 29 julio 2020 - aceptado: 14 noviembre 2020

\begin{abstract}
Resumen
Este trabajo se propone la realización de un análisis distributivo a partir de datos provenientes de imágenes satelitales para Argentina. La ventaja de esta información satelital radica en que permite observar qué ocurre con el bienestar de áreas del país no abarcadas por la Encuesta Permanente de Hogares (EPH). De esta manera, el trabajo realiza un análisis comparativo de la evolución de la pobreza y la desigualdad utilizando ambas fuentes de información, indicando posibles complementariedades entre ellas. Más precisamente, los resultados sugieren que tanto la pobreza como la desigualdad son más altas en áreas no incluidas en la encuesta de hogares, aunque siguen una dinámica similar respecto a los aglomerados urbanos de la EPH.
\end{abstract}

Códigos JEL: D31, I30, I32.

Palabras clave: pobreza, desigualdad, información satelital, Argentina.

\footnotetext{
Abstract

The aim of this paper is to perform a distributive analysis using satellite data for Argentina. The use of this information has the advantage of permitting to observe

Agradezco los valiosos comentarios y sugerencias de Luciana Galeano, Leonardo Gasparini y Leopoldo Tornarolli. Todos los errores y/o omisiones son responsabilidad del autor.

- Ciaschi, M. (2021). Análisis distributivo utilizando información satelital. El caso de Argentina. Estudios económicos, 38(77), pp. 5-38. DOI: https://doi.org/10.52292/j.estudecon.2021.2116

* Centro de Estudios Distributivos, Laborales y Sociales (CEDLAS). Instituto de Investigaciones Económicas, Facultad de Ciencias Económicas, Universidad Nacional de La Plata, Argentina. ORCID: https://orcid.org/000-0002-2288-0315. Correo electrónico: matiasciaschi@gmail.com
} 
welfare in areas not included in the Encuesta Permanente de Hogares (EPH). This paper performs a comparative analysis on the evolution of poverty and inequality trends using both information sources, pointing out possible complementarities between them. More precisely, results suggest that both poverty and inequality are higher in areas not included in the household survey, despite these trends follows similar patterns compared to urban areas included in the EPH.

JEL Codes: D31, I30, I32.

Keywords: poverty, inequality, satellite data, Argentina. 


\section{INTRODUCCIÓN}

El análisis de las dinámicas de la desigualdad de ingresos y la pobreza es de singular relevancia a la hora de conocer el desarrollo socioeconómico de los países. No en vano se utilizan grandes recursos para financiar encuestas de hogares sumamente útiles para monitorear la evolución de estas variables. Sin embargo, en ocasiones existen problemas ligados a estas encuestas. Entre estos inconvenientes, más allá cuestiones relacionadas a su costo monetario y posibles casos de no respuesta de ingresos, se encuentra el alcance geográfico de la encuesta. Cuando una encuesta de hogar no es representativa del país al poseer un alcance geográfico limitado, pueden surgir errores de estimación de los diversos indicadores socioeconómicos. En particular, problemas de alcance geográfico y representatividad de la muestra son capaces de subestimar los índices de pobreza de una sociedad. Importantemente, este tipo de inconvenientes en las encuestas de hogar ocurren con mayor preponderancia en países en desarrollo, los cuales presentan niveles de pobreza y desigualdad más elevados.

Estas desventajas de las encuestas de hogares incitan a explorar maneras alternativas de monitorear la evolución de la pobreza y la desigualdad de ingresos. Sin ánimo alguno de desacreditar la utilidad de las encuestas de hogares como materia prima para conocer la evolución de estos fenómenos, en este trabajo se propone la utilización de información satelital como instrumento capaz de adicionar información acerca de las dinámicas de dichas variables sociales. En particular, se propone evaluar la utilidad de dicha información, de enfoque espacial, como complemento del limitado alcance geográfico de los microdatos de la Encuesta Permanente de Hogares (EPH) en Argentina. La EPH posee información para 31 aglomerados de más de 100000 habitantes y solo 10 de ellos se encuentran disponibles de manera comparable desde el año 1992. Por otro lado, los datos satelitales no solo cubren a los aglomerados urbanos de la EPH sino también áreas urbanas no abarcadas en esta encuesta. De esta manera, estos datos brindan cierta información que la encuesta de hogar no recoge. Al utilizar imágenes satelitales, el foco del análisis se moverá desde un nivel individual o familiar, propio de las encuestas de hogares, hacia un nivel de microáreas geográficas de elevada resolución. Para ello, este trabajo utiliza como insumo datos satelitales de emisión de luminosidad, también llamados "luces en la noche", provenientes del Defense Meteorological Satellite Program (DMSP) y la National Oceanic and Atmospheric Administration (NOAA). Dicha base de datos contiene información sobre intensidad de luces emitidas desde la Tierra hacia al espacio exterior provenientes de la actividad humana para un período consecutivo de 21 años. 
Desde la contribución de Henderson et al. (2012), la literatura reciente ha utilizado estos datos de intensidad de luces como proxy de evolución de la actividad económica o de los ingresos. En este sentido, diferentes aportes han dado cuenta de la utilidad de estos datos para aquellos países con cuentas nacionales de baja calidad o con encuestas de hogares de representatividad geográfica o temporal limitada. Teniendo en cuenta esto y contando también con información de tipo censal sobre población, este trabajo pretende aproximar el ingreso per cápita mediante la construcción de una variable de intensidad de luces per cápita en Argentina. Luego, se realiza un análisis de tipo distributivo sobre esta variable. Más precisamente, este trabajo estudia en qué sentido se pueden evaluar tasas de pobreza y medidas de desigualdad utilizando la variable de intensidad de luces per cápita.

Los resultados de este trabajo indican que las mediciones de pobreza y desigualdad calculadas a partir de intensidad de luces per cápita agregan información a sus análogas obtenidas a partir de encuestas de hogares en Argentina. De este modo, este trabajo contribuye generando información sobre el bienestar de áreas geográficas sobre cuales no se cuenta con información en la EPH. En particular, se encuentra que tanto la tasa de pobreza como el índice de Gini siguen patrones similares utilizando una u otra fuente de información. El trabajo también encuentra que las áreas geográficas fuera del alcance de la EPH poseen tasas de pobreza y desigualdad más elevadas que aquellas sí incluidas en la encuesta. No obstante, las mediciones de pobreza y desigualdad a partir de intensidad de luces no son capaces de reproducir las constantes caídas en dichos índices que surgen a partir del procesamiento de encuestas de hogares para la década del 2000. La razón detrás de esto parece ubicarse en el hecho de que existe una significativa caída en intensidad de luces en Argentina durante la crisis de 2008-2009. Adicionalmente, y como era esperable dada la naturaleza espacial de los datos satelitales, las estimaciones de pobreza y desigualdad con dichos datos poseen una variación más acotada respecto a aquellas enfocadas a nivel individual o familiar, es decir, utilizando encuestas de hogares.

\section{ANTECEDENTES EMPÍRICOS}

La literatura relacionada a la utilización de información de tipo satelital como insumo para la medición de variables socioeconómicas es sumamente reciente, por lo que no abundan trabajos que utilicen dichos datos con esos fines. Más aún, son todavía más escasas las contribuciones que refieran a algún tipo de análisis distributivo utilizando imágenes satelitales. 
Por un lado, existe una serie de trabajos tendientes a utilizar la luminosidad emanada al espacio exterior como proxy del crecimiento económico, remarcando su utilidad para países cuya calidad de información de cuentas nacionales resulta dudosa. El primer trabajo que es posible mencionar al respecto se encuentra en Sutton et al. (2007), donde los autores encuentran una correlación de alrededor de $70 \%$ entre la evolución de los valores de luminosidad y PBI a nivel provincial (estatal) entre los años 1992 y 2000 para Estados Unidos, Turquía, India y China. Adicionalmente, Sutton et al. (2007) encuentran que dicha correlación se refuerza al realizar ciertos controles adicionales quitando valores extremos y controlando por población de cada provincia. Luego de este incipiente uso de información satelital como aproximación del crecimiento económico, es posible mencionar el trabajo de Chen y Nordhaus (2011) como el primero en establecer un modelo estadístico formal para el análisis de la utilidad de la intensidad de luces a la hora de predecir variaciones en el PBI. Los autores proponen un novedoso enfoque en el cual el PBI "verdadero" es estimado como una combinación de PBI de cuentas nacionales y luminosidad satelital. Luego, se estiman mediante un modelo formal las participaciones de estos dos componentes. El trabajo muestra cómo la intensidad de luces agrega información útil para predecir el crecimiento económico entre los años 1992 y 2008 de manera más precisa, en especial para países con cuentas nacionales débiles. Siguiendo con esta línea, se encuentra tal vez el trabajo más conocido relativo al uso de luminosidad como proxy del crecimiento económico. En Henderson et al. (2012) se presenta un enfoque estadístico similar al que es posible encontrar en Chen y Nordhaus (2011). Sin embargo, representa hasta la fecha el artículo capaz de identificar con mayor robustez una fuerte relación entre crecimiento del PBI y variación en la intensidad de luces. Los autores encuentran que tanto la evolución de la luminosidad en sí como del porcentaje del área geográfica con luminosidad positiva son fuertes predictores del crecimiento económico en el período 19922008, incluso realizando variados controles por otros factores capaces de afectar las dinámicas del PBI. Adicionalmente, en Henderson et al. (2012) es posible identificar un análisis claro acerca de las razones por las cuales la evolución de intensidad de luces es capaz de predecir cambios en el PBI pero el nivel de emisión de luces no permite identificar niveles de producto: razones poblacionales, geográficas y hasta culturales afectan los valores de luminosidad, por lo cual la comparación entre países mediante esa variable no puede ser tan directa.

Por otro lado, existe una serie de trabajos tendientes a utilizar la evolución de intensidad de luces como aproximación del crecimiento económico local no como un fin en sí mismo sino con el objetivo de encontrar un factor de explicación del mismo ya asumiéndolo como buen proxy del ingreso per cápita. Uno de ellos se encuentra en Michalopoulos y Papaioannou (2012), donde se estima la relación 
entre instituciones precoloniales en países africanos y el producto bruto interno actual aproximado por evolución en luminosidad. Explotando variaciones hacia dentro de los países, los autores encuentran un mayor crecimiento económico para regiones donde históricamente existieron instituciones más centralizadas y jerárquicas. Adicionalmente, dentro de este grupo de trabajos es posible mencionar a Hodler y Raschky (2014) donde se evalúa en qué medida existe favoritismo político de los líderes cuando ganan una elección. Más específicamente, los autores encuentran cómo los gobernantes benefician relativamente más a sus localidades de origen al llegar al poder. Dicho beneficio es medido a través de variaciones promedio de la intensidad de luces per cápita por localidad, representando el primer trabajo interesado en la importancia de medir luminosidad promedio por persona.

Por último, dentro de los trabajos interesados en utilizar la información satelital de intensidad de luces con el fin de realizar análisis distributivos es posible comenzar mencionando a Noor et al. (2008) y Elvidge et al. (2009). En el primer caso, los autores estiman pobreza para microáreas en un grupo de países africanos en el año 2000 encontrando una correlación estrecha entre la pobreza medida por luminosidad y la reportada por encuestas de hogares. Por otro lado, en Elvidge et al. (2009), los autores estiman un mapa global de pobreza para el año 2004 a nivel país teniendo en cuenta el porcentaje de píxeles dentro de cada nación con luminosidad nula y, luego, ajustando esa proporción mediante tasas de pobreza reportadas por el Banco Mundial. Si bien en estos trabajos no se evalúa una serie de tasa de pobreza ni se realiza un análisis geográfico más desagregado, ciertamente representan los primeros análisis de tipo distributivo utilizando este tipo de información satelital. A su vez, la metodología de estimación de pobreza presente en Elvidge et al. (2009) ha sido utilizada por trabajos más recientes tales como Smith y Wills (2017), quienes analizan pobreza y desigualdad rural producto de incrementos abruptos en los precios del petróleo a partir de considerar como pobres a las poblaciones viviendo en píxeles con luminosidad nula. Por otro lado, en un análisis a nivel provincial para China, Wang et al. (2012) encuentran que los datos de "luces en la noche" predicen con bastante precisión a la pobreza de ingresos y también a diferentes índices de pobreza. Lo mismo ocurre en Mveyange (2015), donde el autor utiliza información de luminosidad para estimar desigualdad regional en países africanos. El trabajo encuentra que la desigualdad en la región cayó entre 2000-2012 midiéndola a partir de dicha fuente, a diferencia de los resultados provenientes de estimaciones de encuetas de hogares en los cuales se incrementó la dispersión de ingresos. Adicionalmente, el trabajo muestra que el canal de mayor importancia para esta caída en la desigualdad se encuentra en la dinámica de la desigualdad hacia dentro de los países. En el artículo de Pinkovskiy y Sala-i-Martin (2016) se utiliza información satelital sobre intensidad de luces como proxy del PBI y se plantea un modelo simi- 
lar al presente en Henderson et al. (2012) para combinar dicha información con aquella proveniente de cuentas nacionales. Luego de estimar el "PBI verdadero", lo utilizan como variable de ingreso para computar tasas de pobreza a un dólar PPA a nivel nacional para varios países del mundo. Por último, el análisis distributivo utilizando datos de luminosidad en la noche ha sido complementado en algunos trabajos con otro tipo de información satelital en horas del día, tal como Jean et al. (2016) y Engstrom et al. (2017). De esta manera, estos trabajos no solo tienen información sobre luminosidad promedio por localidad, sino que también son capaces de identificar otras características relativas a la disponibilidad de ciertos activos en la zona. Luego de computar tasas de pobreza utilizando esos datos, los resultados arrojan una fuerte relación entre esta información combinada y la tasa de pobreza estimada mediante encuestas de hogares para un grupo de países africanos.

\section{DATOS Y METODOLOGÍA}

La información satelital acerca de intensidad de luces emitidas al espacio exterior proviene del Defense Meteorological Satellite Program / Operational Linescan System (DMSP-OLS) dependiente de la Fuerza Aérea de Estados Unidos y la National Oceanic and Atmospheric Administration (NOAA). Estos institutos poseen satélites orbitando la Tierra con información comparable disponible al público entre los años 1992 y 2013. Para los años 2014-2018, el NOAA comenzó a utilizar otro tipo de sensor en sus satélites (Visible Infrared Imaging Radiometer Suite, VIIRS) y, hasta el momento, no ha realizado ningún tipo de armonización entre los datos de los dos períodos. En el presente artículo, se prefiere trabajar con la base de datos que abarca el período 1992-2013 de manera de poder presentar un análisis distributivo de largo plazo utilizando información satelital. Los satélites observan cada punto del planeta todas las noches en algún momento entre las 8:30 y las $10 \mathrm{pm}$, hora local. El momento preciso en el que se obtiene la imagen satelital cambia dentro de ese rango horario de manera de obtener datos de luminosidad siempre al mismo ángulo de elevación del sol a lo largo del año. El mismo NOAA se encarga de procesar los datos obtenidos de esta manera removiendo "ruidos" tales como meses del año en el que el sol se pone tarde, cobertura de nubes y otras formas de fuentes de luces naturales ajenas a la actividad humana, como pueden ser volcanes o incendios. Finalmente, los datos obtenidos por cada satélite en cada año se obtienen de promediar el valor correspondiente a cada una de las noches válidas, es decir, aquellas que sobrevivieron a la remoción de "ruidos". Según reporta la NOAA, se utilizan en promedio 39.2 noches "válidas" para obtener la base de datos anual. Solo luego de estos procesos es que los datos se distribuyen públicamente, 
por lo que en este trabajo se utilizan las imágenes satelitales disponibles luego de que la NOAA las procese ${ }^{1}$.

En definitiva, este trabajo hace uso de una base de datos en la que se identifica cada píxel del territorio nacional y la intensidad de luces en ellos. Estos píxeles poseen una extensión de 30 arcosegundos (aproximadamente un kilómetro cuadrado en el ecuador $)^{2}$. La variable de intensidad de luces toma valores enteros en un rango que va de 0 , en píxeles donde los satélites no captan luminosidad, a 63 (luminosidad máxima). En los datos, una fracción muy pequeña de píxeles posee esta censura en cuanto a su límite superior: $0.04 \%$ en 1992 y $0.15 \%$ en 2013 . Por otro lado, dentro de los píxeles con valores de luminosidad igual a cero se encuentran observaciones que poseen intensidades de luces tan bajas que los satélites no pueden captar, así como observaciones donde realmente la luminosidad es nula. Por esta razón no es posible identificar la heterogeneidad existente en cuanto a luminosidad dentro del universo de píxeles con valores nulos de dicha variable. Este punto está estrictamente relacionado con el grado de desarrollo de la infraestructura del país y, particularmente, al acceso a la energía eléctrica. Una ventaja de estudiar la evolución en la intensidad de luces en un país como Argentina radica en su amplio acceso eléctrico durante el período analizado. En la figura 1 se expresa la evolución del acceso a la energía eléctrica, tanto para el total del país como diferenciando por zonas urbanas y rurales, a partir de datos del Banco Mundial y de la Organización Latinoamericana de Energía (OLADE). Como puede observarse, durante todo el período analizado más del $90 \%$ de la población poseía conexión a electricidad, la cual logra abarcar prácticamente a toda la población en los últimos años de estudio. Los resultados de este trabajo deben ser considerados teniendo en cuenta este aspecto. Si bien la diferencia entre la población total y aquella con acceso eléctrico no es considerable, el análisis aquí provisto es representativo solo del segundo grupo. Esto quiere decir que, en principio, la tasa de pobreza y la desigualdad serían levemente superiores si los datos pudieran abarcar al total de la población y no solo a aquella con acceso eléctrico. El alto grado de acceso eléctrico en el país indica que la magnitud de esta diferencia no sería considerable. Sin embargo, la posibilidad de que exista alguna diferencia posiblemente se distribuya de manera heterogénea a

1 Más información acerca del procesamiento de los datos satelitales por parte del NOAA puede encontrarse en: https://www.ngdc.noaa.gov/eog/dmsp/downloadV4composites.html. Allí también es posible descargar estos datos.

2 La extensión en metros de cada arcosegundo depende de la latitud geográfica. En el caso de Argentina, cada arcosegundo representa aproximadamente 0.8 kilómetros cuadrados en sus límites más septentrionales, 0.32 kilómetros cuadrados en su límite sur y 0.64 kilómetros cuadrados para latitudes semejantes a la ciudad de Buenos Aires. 
lo largo del territorio: es más probable que las mismas existan en zonas de menor conexión eléctrica.

Figura 1. Acceso eléctrico en Argentina por zonas geográficas

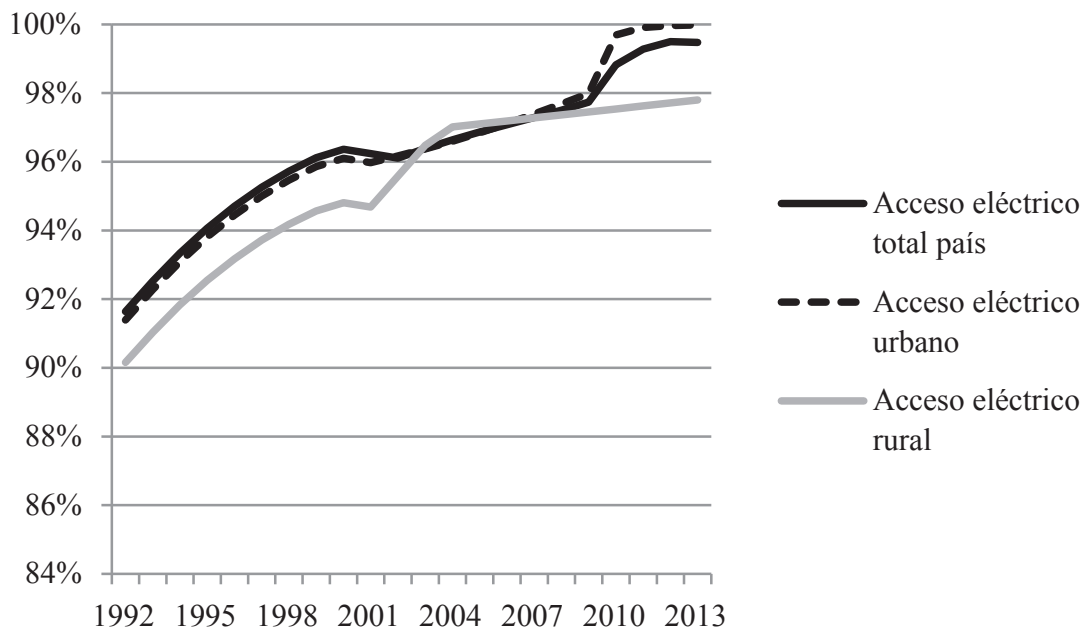

Fuente: elaboración propia sobre la base de Banco Mundial y OLADE.

La intensidad de luces reportada en cada píxel del territorio refleja el consumo tanto en el interior como en el exterior de las viviendas. Las luces reportadas fuera de ellas suelen estar, en parte, ligadas a cuestiones de infraestructura como podría ser el alumbrado público. Salvo en el caso de la ocurrencia de eventos catastróficos, este componente no debería cambiar fuertemente en el tiempo o en todo caso debería estar asociado a la evolución de la tendencia del producto interno bruto de un país, más que a fluctuaciones cíclicas. Las luces al interior de las viviendas, en cambio, o incluso aquellas al exterior de las mismas pero que tienen que ver con emprendimientos privados (como teatros, hoteles, eventos, etc.), sí parecen estar más asociadas a componentes cíclicos del ingreso de un país, y por ende es en estos casos donde es posible observar una mayor variabilidad en el tiempo. Prácticamente todo tipo de consumo requiere, directa o indirectamente, algún tipo de luces. De esta manera, a medida que el ingreso de un área se incrementa es esperable que así también lo haga la generación de luces por persona, al menos en promedio. En la figura 2 es posible observar un mapa que muestra la distribución geográfica de la intensidad de luces para Argentina. 
Figura 2. Distribución geográfica de intensidad de luces en Argentina

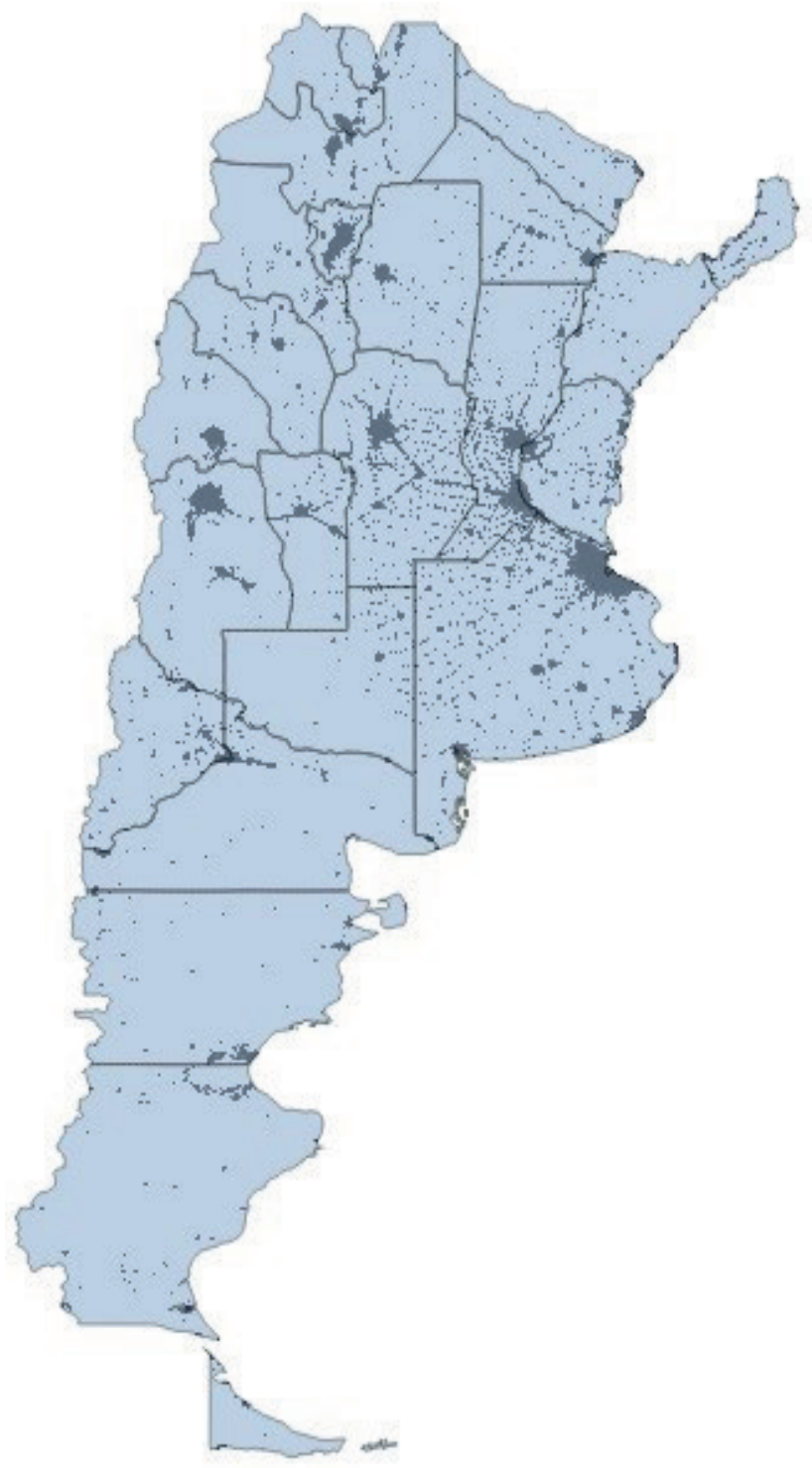

Fuente: elaboración propia sobre la base de NOAA. 
Otro punto a tener en cuenta respecto a los datos asociados a la intensidad de luces radica en el hecho de que dicha variable toma valores altos no solo en píxeles donde habitan poblaciones más ricas en ingreso, sino también en aquellos donde la densidad poblacional es mayor. Es por esta razón que, por ejemplo, se podría encontrar un valor promedio de intensidad de luces menor en países desarrollados respecto a otros países donde se conoce que su nivel de ingreso promedio es marcadamente menor. Este hecho posee dos implicancias: primero, la información sobre luminosidad emanada por cada píxel solo ofrece, por sí sola, una buena aproximación de la evolución del ingreso, pero no de su nivel (Henderson et al., 2012). Segundo, es necesario realizar algún tipo de control por población. Consecuentemente, en este trabajo se utiliza información sobre población también a nivel de píxel de manera de computar intensidad de luces per cápita (en adelante, llamaremos a esta variable simplemente "intensidad de luces"), y luego se evalúa la evolución de dicha variable en términos distributivos. Los datos de población para cada píxel del territorio provienen de la Gridded Population of The World, dependiente de la National Aeronautics and Space Administration (NASA) y el Center for International Earth Science Information Network (CIESIN) de la Universidad de Columbia. Esta información está basada en censos nacionales y está disponibles cada cinco años desde 1990. Con el fin de obtener el valor de la población en cada píxel para cada año entre 1992 y 2013, en este trabajo se realiza una interpolación lineal a partir de los datos de población obtenidos de la misma manera que lo hacen Hodler y Raschky (2014).

Las fuentes de información anteriormente mencionadas utilizadas en este trabajo se encuentran en formato de imágenes. Para obtener una base de datos numérica a partir de las imágenes satelitales se utiliza el software QGIS. Como este trabajo se enfoca en lo ocurrido en Argentina, fue necesario identificar los límites del país dentro de las imágenes satelitales. En este sentido, se utilizan archivos que contienen información sobre la ubicación geométrica de las entidades geográficas (shapefiles) provenientes de la base de datos Global Administrative Areas (GADM) teniendo la precaución de que los mismos contengan la misma proyección global que los datos relativos a la emisión de luces y población por pixel. Estos shapefiles permiten identificar a qué localidad dentro de cada provincia pertenece cada píxel. De esta manera es posible reconstruir, de manera aproximada, tanto los aglomerados urbanos de la EPH (Encuesta Permanente de Hogares) como también una definición de urbanidad más amplia incluyendo otros núcleos urbanos y permitiendo la comparabilidad entre ambos conjuntos de aglomerados. Una ventaja adicional de utilizar este tipo de información satelital para análisis de tipo distributivo radica en que, a diferencia de prácticamente todas las encuestas de hogares, es posible identificar las observaciones (pixeles) a lo largo de todo el período. Es decir, es posible determinar la evolución en la intensidad de luces para cada píxel del territorio. 
Atendiendo a las particularidades del caso argentino, el considerable abaratamiento del precio de la energía eléctrica ocurrido desde, aproximadamente, el año 2006 podría sesgar las estimaciones presentadas en este trabajo. Más precisamente, dicho fenómeno permite que sea cada vez más accesible consumir cierto umbral de intensidad de luces por lo que, por ejemplo, las tasas de pobreza medidas por dicha variable podrían estar subestimadas. Por esta razón, se decidieron ajustar los valores de intensidad de luces por la evolución del consumo residencial eléctrico de cada provincia multiplicado por la elasticidad precio estimada de acuerdo a la literatura relacionada al tema, en particular Hancevic y Navajas (2013)3. Para ello, se utilizó información proveniente del Ministerio de Energía y Minería de la Nación. La serie de intensidad de luces realizando y no realizando el ajuste debido al abaratamiento en el costo de la energía eléctrica se encuentra en el apéndice A. Allí es posible ver cómo, al realizarse dicho ajuste, la luminosidad por persona disminuye en un promedio de $0.51 \%$ y $1.99 \%$ para períodos anteriores y posteriores al año 2006 , respectivamente. Como consecuencia de esto, la tasa de pobreza luego del ajuste en la luminosidad es apenas más alta que si dicho ajuste no se realizara. En principio, este ajuste no debería generar consecuencias relevantes en términos de desigualdad. Esto es así ya que, por ejemplo, tanto el índice de Gini como las Curvas de Incidencia del Crecimiento (CIC) son medidas de desigualdad invariantes a la escala.

El objetivo principal de este trabajo radica en comparar la evolución de la pobreza y la desigualdad en Argentina computadas a partir de la EPH y de datos satelitales de luces, teniendo en cuenta que estos últimos abarcan zonas urbanas excluidas en la encuesta de hogar. En lo concerniente a la información de la EPH, se utilizan las bases de datos que provee el Instituto Nacional de Estadísticas y Censos (INDEC). Luego, las mismas se procesan siguiendo la metodología de SECLAC (2020). Este procedimiento, detallado también en Tornarolli (2018), permite obtener series de pobreza y desigualdad comparables desde el año 1992 para Argentina. Por otro lado, los datos satelitales de luces también permiten obtener series de estos indicadores de manera comparable para el período 1992-2013. Siguiendo a Elvidge et al. (2009), y como se discutirá más en detalle en la sección IV, se consideran como pobres a aquellos píxeles de luminosidad nula. Este es un procedimiento habitual en la literatura que utiliza este tipo de datos satelitales para medir pobreza y, además, permite obtener tasas de pobreza al inicio del período de análisis similares entre ambas fuentes de datos. En cuanto a la evolución de la desigualdad utilizando datos de luminosidad, explicada en más detalle en la sección V de este trabajo, se computa el índice de Gini así como curvas de incidencia del crecimiento a partir de la luminosidad de los píxeles.

3 Los autores estiman una elasticidad precio del consumo eléctrico de alrededor 0.25 en valor absoluto. 
Una vez obtenidas las series de desigualdad y pobreza utilizando ambas fuentes de datos, este trabajo se propone realizar una comparación entre ellas. A partir de ello, es posible evaluar en qué sentido la información de tipo satelital agrega información socioeconómica respecto a la que ofrece la EPH, que abarca un conjunto de aglomerados urbanos más acotado. En este sentido, un punto importante concerniente a los datos satelitales disponibles radica en el hecho de que para que sea posible la utilización de esta información para realizar análisis distributivos es necesario cambiar el nivel de análisis respecto a aquel que posibilitan las encuestas de hogares. En particular, estas últimas poseen información a nivel individual o familiar mientras que los datos satelitales se encuentran a nivel microgeográfico (píxel). Es por esta razón que el análisis presentado en este trabajo debe interpretarse como un complemento de aquel realizado mediante la EPH y no como sustituto del mismo.

\section{INTENSIDAD DE LUCES COMO VARIABLE DE BIENESTAR}

En esta sección se discute en qué medida la variable computada de intensidad de luces puede representar el bienestar en las microáreas geográficas analizadas. Esto es particularmente relevante para este estudio ya que de existir grandes discrepancias entre la medida de bienestar propuesta aquí y otras variables de bienestar (como el PBI per cápita), surgirían dudas respecto a la pertinencia en utilizar la intensidad de luces para realizar un análisis de tipo distributivo. En este sentido, esta sección se propone evaluar en qué medida la evolución de las variables de luces y PBI per cápita, como proxies de bienestar, es similar.

Como fuera mencionado anteriormente, los antecedentes empíricos muestran cómo la evolución en la luminosidad (sin controlar por población) representa un buen proxy de la actividad económica de los países. Sin embargo, antes de realizar cualquier tipo de análisis distributivo para el caso de Argentina, es relevante considerar en qué medida la variable de intensidad de luces que computa este trabajo está relacionada con el PBI per cápita del país. Es decir, es preciso tener en cuenta si es posible pensar a la intensidad de luces como aproximación del ingreso per cápita, y por ende el bienestar, en cada microárea geográfica. La figura 3 muestra la evolución conjunta de la variable de luminosidad per cápita y el PBI per cápita, a paridad de poder adquisitivo (PPA, PPP en inglés) y a dólares constantes, obtenidos del World Development Indicators (WDI) del Banco Mundial. La correlación existente entre las series es de $70 \%$ en el primer caso y $77 \%$ en el segundo, que representan valores similares a los que se encuentran en la literatura. Más allá de esta evolución similar de las series, es necesario destacar la caída en intensidad de luces para el país durante la crisis 2008-2009. Como se verá más adelante, este 
hecho no será inocuo a la hora de realizar las estimaciones de pobreza y desigualdad considerando dicha variable como medida de bienestar.

Figura 3. Relación entre intensidad de luces y PBI per cápita
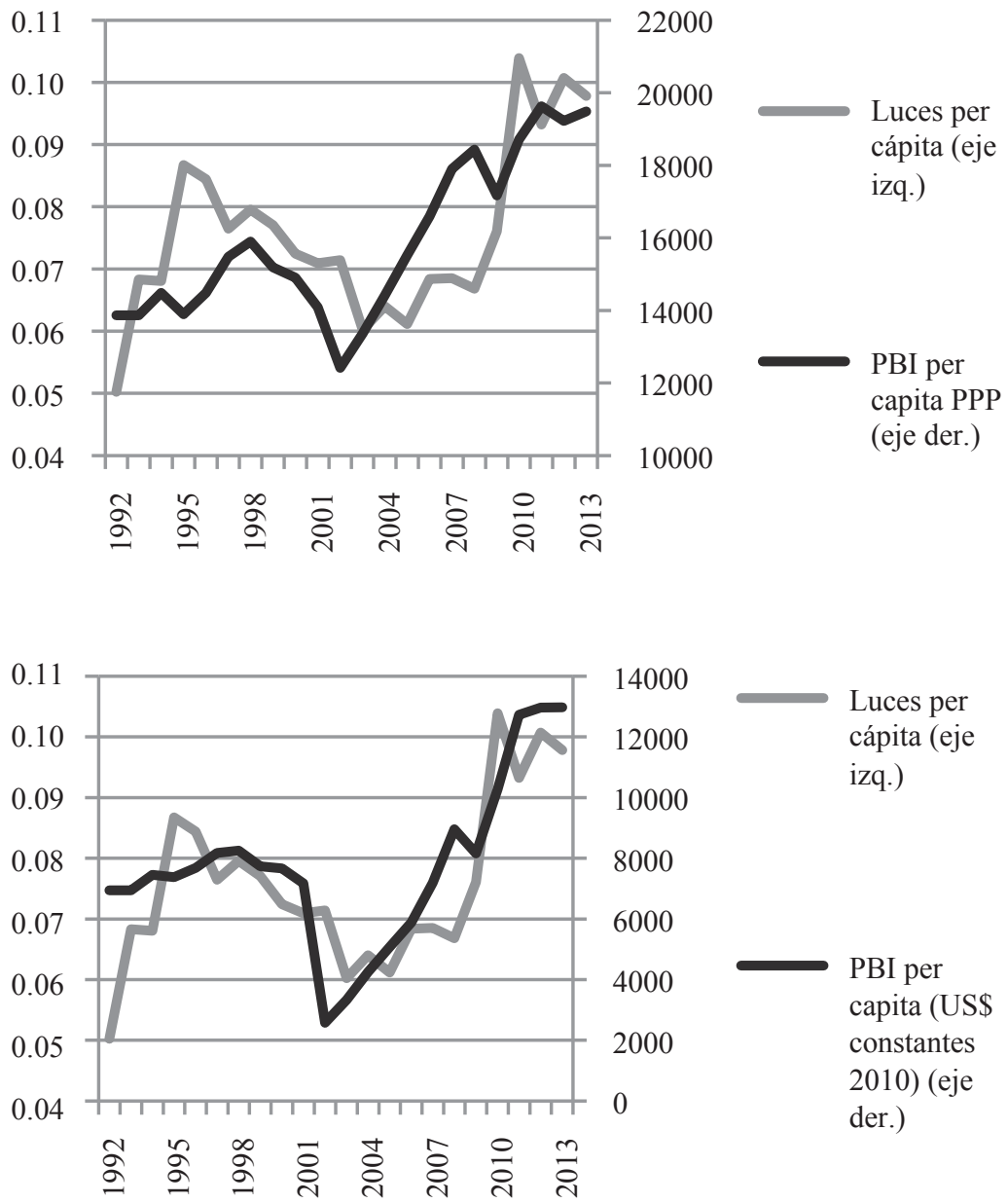

Fuente: elaboración propia sobre la base de NOAA, CIESIN y WDI del Banco Mundial. 
Como fuera explicado anteriormente, la variable de intensidad de luces computada en este trabajo posee un componente poblacional ya que se calcula per cápita. Esto se ha hecho así por dos motivos: por un lado, como establece la literatura, el nivel de intensidad de luces sin componentes poblacionales (es decir, sin dividirlo por población) no representa una buena aproximación del ingreso en un país o área; y por otro, y más importante, en este trabajo se propone establecer en qué cuantía el crecimiento económico de cada microárea geográfica beneficia, en promedio, a cada persona que habita en ella. De esta manera, es posible pensar a la variable de intensidad de luces como proxy del ingreso per cápita de cada píxel geográfico. Llegado a este punto es necesario enfatizar el hecho de que la información disponible permite aproximar el bienestar de cada individuo habitando en cada píxel solo en promedio. Sin embargo, se desconoce cuál es la distribución del ingreso per cápita aproximado de esta manera al interior de cada microárea. En este trabajo se supone que la misma es homogénea dentro de cada píxel, de manera que toda la población que habita en él se asume con el mismo nivel de ingreso o bienestar4.

Naturalmente, las características propias de la variable de intensidad de luces se trasladan al análisis de las dinámicas de las estimaciones de pobreza y desigualdad cuando se la utiliza con ese propósito. Primeramente, es necesario subrayar que todo análisis de este tipo utilizando información satelital es de carácter espacial, no individual. Más allá de que los datos disponibles permiten un nivel de desagregación geográfica considerable, cualquier estudio a partir de ellos solo converge al análisis individual sin dejar de ser el mismo de tipo espacial. Es por esta razón que, al computar medidas de desigualdad, no es factible identificar la posible dispersión en ingresos aproximados existente dentro de cada píxel y solo se considerará variabilidad en la intensidad de luces promedio de cada uno de ellos. Si bien cada microárea geográfica tendrá en las estimaciones de desigualdad un peso adecuado a la población que contiene, ciertamente solo se computará dispersión de luminosidad promedio entre píxeles. En cuanto a las estimaciones de pobreza a partir de intensidad de luces, el hecho de que la unidad de análisis se encuentre a nivel de píxel tiene también sus implicancias. Debido a que el objetivo del trabajo radica en computar la tasa de pobreza por intensidad de luces, se considerará como pobre a toda la población perteneciente a píxeles cuya luminosidad promedio se encuentre por debajo de cierta "línea de pobreza de luces" y como no pobre en caso contrario. Al hacer esto, el supuesto de homogeneidad dentro de cada microárea

4 Este podría ser un supuesto fuerte en áreas de marcada segregación espacial en las cuales cabe la posibilidad de que un píxel contenga población que habite en circunstancias heterogéneas, más allá de su proximidad geográfica. 
en la distribución de luminosidad es sumamente importante ya que se asume que todos los individuos pertenecientes a cada una de ellas se encuentran en la misma situación de suficiencia o insuficiencia de ingresos. Esta particularidad representa una limitación en los datos: dentro de un mismo píxel pueden convivir individuos cuya situación de pobreza es distinta. Si bien este supuesto podría parecer demasiado simplista para un análisis de pobreza a nivel individual, podría no serlo en el caso de este trabajo en que se analizan microáreas geográficas. Uno de los objetivos de este trabajo radica en evaluar en qué sentido las tasas de pobreza por intensidad de luces siguen tendencias similares a aquellas computadas a partir de ingresos de la EPH, lo cual se considera en la sección IV. La evolución de la pobreza medida por luminosidad no debería cambiar si se supone que dentro de cada píxel pobre existe un porcentaje de individuos no pobres o viceversa. Sí podría cambiar el nivel de la tasa de pobreza dependiendo de qué supuestos se realicen para establecer ese porcentaje. Sin embargo, los resultados que se muestran en este trabajo, acerca de si los datos satelitales permiten ampliar la cobertura de un análisis distributivo respecto a aquel que permite la $\mathrm{EPH}$, no cambiarían.

Este trabajo se abstrae de otro tipo de discusiones concernientes al uso de información satelital de intensidad de luces como medida de bienestar. Como fuera mencionado anteriormente, la emisión de luces durante la noche refleja actividad dentro y fuera de la vivienda ya sea privada o pública. Adicionalmente, la actividad económica realizada durante el día no es captada por esta información. Este trabajo no tiene como objetivo comparar consumo eléctrico privado versus público ni consumo eléctrico durante la noche versus durante el día. Tampoco se pretende identificar en qué medida factores ligados al progreso tecnológico o economías de escala son capaces de afectar la demanda de electricidad. Por último, este trabajo no considera cuestiones relacionadas al acceso a otras fuentes de energía no eléctricas, como puede ser el gas natural, en la determinación del nivel de luminosidad. A medida que el ingreso de las personas crece, es esperable que lo haga así también el consumo generando mayor luminosidad, independientemente de si la fuente de energía que posibilita el consumo es eléctrica o no. De esta manera, se incrementa la intensidad de luces en un área geográfica determinada. Este fenómeno es el que se intenta explotar en este trabajo. Los puntos mencionados anteriormente que quedan fuera del foco de análisis de este trabajo representan un campo fértil para futuras investigaciones más allá de la literatura concerniente a estudios distributivos. Por ejemplo, dichos aspectos pueden ser abarcados por la literatura que estudia la pobreza energética, concepto que hace referencia a situaciones en las que el ingreso de los hogares no es suficiente para atender sus demandas domésticas de electricidad (véase Martín et al., 2020 para una discusión de este concepto en el caso argentino). 


\section{POBREZA POR INTENSIDAD DE LUCES}

En esta sección se presentan los resultados de las estimaciones de pobreza mediante intensidad de luces para Argentina entre 1992 y 2013. A grandes rasgos, los resultados indican que dichas estimaciones siguen una evolución similar a aquellas que utilizan información proveniente de encuestas de hogares a nivel individual. Ambas fuentes reportan un incremento en la tasa de pobreza en la década de 1990, seguido de una caída en la misma para la primera década del siglo XXI y, por último, un estancamiento en la caída de la tasa pobreza para los años posteriores a 2010. Sin embargo, debido a la naturaleza de tipo espacial de los datos satelitales, la variación de la tasa de pobreza utilizando dicha fuente de información es más acotada respecto a la que surge de cómputos mediante ingresos individuales de la EPH. Esto último puede ser explicado principalmente por dos razones: el componente más estructural de la variable de intensidad de luces respecto a las variables de ingreso y, principalmente, al cambio en el nivel de análisis que implica el uso de información satelital desde un nivel individual a uno de microáreas geográficas. A su vez, debido a la caída en intensidad de luces agregada durante la crisis de 2008-2009, la serie estimada de tasa de pobreza mediante datos satelitales posee un incremento durante dichos años. En consecuencia, los cómputos de pobreza utilizando intensidad de luces no reportan una caída continua en dicho indicador para la década del 2000 como sí es posible estimar mediante ingresos individuales de la EPH.

Un punto crucial de este análisis radica en la elección de la línea de pobreza por luces. Cuando se trabaja con datos de ingresos individuales provenientes de encuestas de hogares, típicamente se establecen canastas alimentarias necesarias para alcanzar ciertos requerimientos calóricos mínimos, luego se valorizan y se considera como pobre a toda persona cuyos ingresos no logren alcanzar el valor de dichas canastas. Las estimaciones de pobreza utilizando la EPH en este trabajo siguen esta metodología utilizando las bases de datos procesadas de acuerdo a SEDLAC (2020). Naturalmente, no existe un procedimiento similar para establecer umbrales de pobreza cuando se utilizan datos satelitales de intensidad de luces. Es por esta razón que, siguiendo a Elvidge et al. (2009), en este trabajo se considerará como pobre a toda la población ubicada en píxeles con luminosidad nula. De esta manera, la tasa de pobreza se computará como el porcentaje de la población del país que habita en píxeles con valores de luminosidad iguales a cero ${ }^{5}$. Esto podría traer

5 En este trabajo se decide elegir este umbral ya que resulta el procedimiento común en la literatura. Sin embargo, es necesario tener en cuenta que en el caso argentino el mismo podría estar indicando situaciones entre la indigencia y la pobreza. En lo que sigue se hará referencia a pobreza; no obstante, este punto debe tenerse en cuenta. 
aparejados errores de inclusión al considerar como pobres a personas ubicadas en microáreas geográficas muy escasamente pobladas con niveles de ingresos altos ${ }^{6}$. Con el fin de considerar esta posible limitación, se computaron tasas de pobreza dejando fuera de la muestra aquellos píxeles muy escasamente poblados. Entre ellas, en la figura B3 (apéndice B) se presenta la tasa de pobreza solo para píxeles con luminosidad positiva. Allí, la línea de pobreza por luces se estableció de manera que la población pobre fuera del 13\% en 1992, al igual que la pobreza de ingresos por EPH a 4 dólares PPA. Como podrá observarse más adelante, los resultados obtenidos son similares en evolución a los que se muestran en esta sección. De esta manera, es posible que esta limitación de los datos satelitales para el cálculo de pobreza no sea demasiado restrictiva o, al menos, sea menos relevante respecto a la principal ventaja de este tipo de información en el sentido de abarcar zonas geográficas excluidas en la encuesta de hogar. A su vez, el criterio utilizado para definir la línea de pobreza por intensidad de luces, es decir el porcentaje de la población ubicada en píxeles de luminosidad nula, posee ciertas ventajas. Por un lado, establece una pauta bastante clara respecto a qué píxeles se considerarán pobres; y, por otro, da como resultado una tasa de pobreza para aglomerados urbanos pertenecientes a la EPH similar a la computada por SEDLAC (2020) a 4 dólares PPA al inicio del período de análisis, que es de aproximadamente $13 \%$. En consecuencia, y a los fines comparativos, ambas series poseerán un punto de partida común.

De acuerdo a la información disponible, es posible computar dicha tasa para el total nacional ("Nacional"), aglomerados urbanos semejantes a los de la EPH y aglomerados urbanos en general. Como fue mencionado anteriormente, es posible identificar a qué partidos o departamentos pertenece cada observación, es decir, cada píxel. De esta manera, es posible replicar de manera aproximada los aglomerados existentes en la EPH en la base de datos. A partir de esta identificación, se construye la tasa de pobreza por luces "Urbana-EPH". Adicionalmente, y a partir de datos del INDEC (Instituto Nacional de Estadísticas y Censos) y de World Development Indicators (WDI) del Banco Mundial, se identifica de manera aproximada otros aglomerados urbanos no considerados en la EPH. La información proveniente de WDI es útil para conocer el porcentaje de población rural en cada año en Argentina, mientras que del INDEC es posible obtener el ordenamiento de todas las ciudades argentinas por su población. Luego, simplemente se consideran urbanos a todos los partidos o departamentos que incluyen a una o más de dichas ciudades hasta acumular el porcentaje de población urbana obtenido a partir de

6 En el extremo, si en un píxel habita solo una persona, cabe la posibilidad de que los satélites no sean capaces de captar la actividad en término de luces de esa sola persona más allá de que ella tenga ingresos altos. 
WDI. Se identifica la tasa de pobreza resultante como "Urbana-Total". La tasa de pobreza Nacional, Urbana-Total y Urbana-EPH estimadas mediante intensidad de luces se encuentran representadas en la tabla A1 (apéndice A) y figuras 4 y 5.

Figura 4. Tasas de pobreza por intensidad de luces. Nacional y Total Urbano

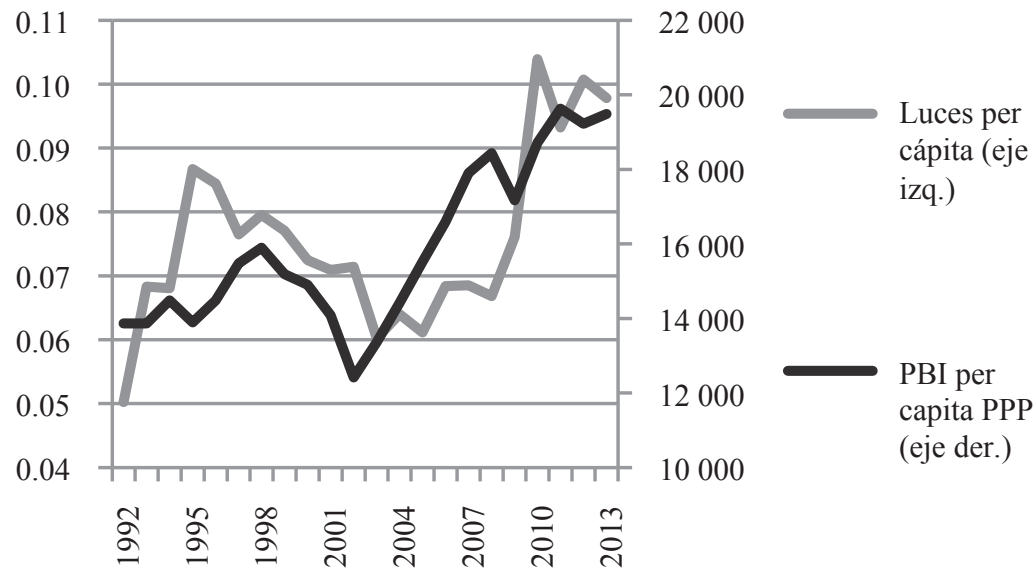

Fuente: elaboración propia sobre la base de NOAA y CIESIN.

Figura 5. Tasa de pobreza por intensidad de luces para Urbano-EPH y por ingresos

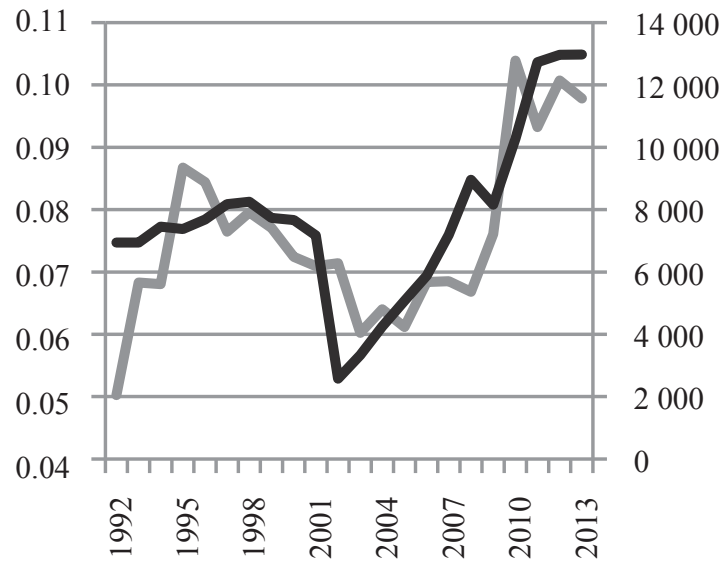

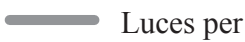
cápita (eje izq.)

PBI per capita (US\$ constantes 2010) (eje der.)

Fuente: elaboración propia sobre la base de NOAA y CIESIN y SEDLAC (CEDLAS y Banco Mundial). 
Las tres alternativas de tasas de pobreza que se han computado, en principio, siguen una tendencia similar: presentan un crecimiento durante la década de 1990, seguido de un decrecimiento en las mismas para el primer decenio de los años 2000 $y$, por último, un estancamiento en dicha caída para los últimos años de la serie e incluso un incipiente crecimiento. No obstante, la caída en los valores de intensidad de luces agregadas para Argentina mencionadas anteriormente para el período de crisis 2008-2009 genera un incremento en la tasa de pobreza que no permite una caída constante de dicho indicador durante la década del 2000.

Más allá de estas dinámicas similares, queda claro que la tasa de pobreza Urbana-EPH presenta valores menores durante toda la serie respecto a su análoga Urbana-Total, a la vez que esta última siempre se encuentra por debajo de la tasa de pobreza Nacional ${ }^{7}$. Por otro lado, y evaluando con más detalle las evoluciones de estos indicadores, en un contexto en que los mismos se incrementaron, como ocurrió en la década de 1990, es posible observar cómo la tasa de pobreza Urbana-EPH presenta un menor crecimiento a sus análogas incluyendo más aglomerados y todo el país. En consecuencia, la participación de los aglomerados urbanos identificados en la EPH en la pobreza total del país fue cayendo en la última década del siglo pasado. Sin embargo, este diferencial en las evoluciones de las tasas de pobreza no se mantiene para los años siguientes del análisis. En particular, cuando dichos índices mejoraron en la primera década de los años 2000, lo hacen a un ritmo similar para las tres alternativas computadas. Es decir, la recuperación económica acontecida en la primera década del siglo XXI parece haber beneficiado, en términos de menores tasas de pobreza, de forma semejante tanto a aglomerados urbanos identificados en la EPH como a la mayoría de los centros urbanos del país.

Con el fin de contextualizar los resultados encontrados, cabe aclarar que los mismos no difieren demasiado en su evolución respecto a las estimaciones de pobreza a 4 dólares PPA por ingresos a partir de la EPH computadas siguiendo la metodología SEDLAC (2020). El coeficiente de correlación entre la tasa de pobreza Urbano-EPH por intensidad de luces y la tasa de pobreza por ingresos de SEDLAC es de $67 \%$ para la serie completa, incrementándose a valores entre $76 \%$ y $92 \%$ si no se consideran los años cercanos a la crisis de 2008-2009 en los cuales la tasa de pobreza se incrementa. Como puede apreciarse, más allá de que el signo de la evolución es similar, la pobreza medida por intensidad de luces cae a menor

7 Si bien este resultado podría ser interpretado como evidencia acerca de que la pobreza de tipo rural en argentina es mayor que su análoga urbana, dentro de esta discusión están involucrados temas referidos a la definición de una línea de pobreza rural adecuada considerando, por ejemplo, las condiciones de acceso al servicio eléctrico de esas zonas. 
ritmo que aquella estimada por ingresos de EPH en la primera década de los años 2000. Una de las principales razones que es posible esbozar para interpretar esta diferencia radica en el incremento de la relevancia de la seguridad social en dicho período. La aparición de programas de transferencia monetaria hacia los hogares menos favorecidos representa un ingreso no laboral poco asociado a la actividad económica y difícil de capturar analizando microáreas geográficas. En este sentido, contribuciones como Tornarolli et al. (2018) y Garganta (2019), este último particularmente para el programa Asignación Universal por Hijo (AUH), dan cuenta de que las transferencias por programas sociales representan uno de los componentes más relevantes para explicar la caída en la pobreza y la desigualdad en Argentina en el siglo XXI. En definitiva, a partir de los resultados presentados en este apartado, es posible pensar a la información proveniente de datos satelitales como un complemento útil a la existente en las encuestas de hogares en el análisis de la dinámica de la pobreza del país.

\section{DESIGUALDAD POR INTENSIDAD DE LUCES}

En esta sección se presenta la evolución de la desigualdad estimada a partir del índice de Gini sobre intensidad de luces para Argentina entre 1992 y $2013^{8}$. Adicionalmente, se presentan mediante Curvas de Incidencia del Crecimiento la evolución de cada decil de la distribución de intensidad de luces en diferentes períodos ${ }^{9}$. Nuevamente, es necesario recordar que las medidas de desigualdad estimadas aquí son de tipo espacial. Es decir que, si bien las microáreas geográficas (píxeles) que se utilizan como unidad de análisis son lo suficientemente pequeñas para converger en buena medida a un estudio en que la unidad de análisis está representada por el individuo o su familia, ciertamente el análisis no deja de ser comparativo entre las mencionadas áreas geográficas.

En los análisis distributivos utilizando datos de ingresos de encuesta de hogar, el cómputo de medidas de desigualdad como el índice de Gini se practica sobre los ingresos positivos. Es decir, se excluyen del análisis a aquellos individuos con ingresos iguales a cero. En este apartado se utilizan los datos de la EPH del proyecto SEDLAC (2020) para computar el índice de Gini siguiendo esta práctica,

8 En resultados no presentados aquí, se han removido observaciones de valores extremos de la distribución de intensidad de luces no cambiando significativamente los resultados respecto a que se exponen.

9 Tanto en el cómputo de los índices de Gini como de las CIC, los píxeles han sido ponderados por la población que habita en ellos de manera que los mismos representen lo más adecuadamente posible la distribución de la población. 
para luego comparar la evolución del mismo a partir de intensidad de luces. En consecuencia, con el objetivo de que ambas medidas sean comparables, se excluye del análisis a aquellos píxeles que reportan luminosidad nula. Debido a esto, una buena parte de la población rural queda fuera del análisis de desigualdad al poseer valores cero de intensidad de luces. De esta manera, y a diferencia de la sección IV referente a las estimaciones de pobreza, en esta sección se omite el análisis de la desigualdad para poblaciones rurales. En consecuencia, en el análisis de la desigualdad por intensidad de luces se comparará su evolución para aglomerados incluidos en la EPH respecto a una definición más amplia de urbanidad que comprende aglomerados adicionales, tal como fueran definidos en la sección IV.

Los resultados encontrados en este apartado sugieren un incremento en la desigualdad medida por intensidad de luces en la década de 1990, seguido de un decrecimiento para la década siguiente y, por último, una tendencia aproximadamente constante para los últimos años bajo análisis. Estas dinámicas resultan similares a las estimaciones de índice de Gini sobre el ingreso per cápita familiar computado por el proyecto SEDLAC (2020) utilizando microdatos de la EPH. Debido a la naturaleza de los datos satelitales, el rango de variación del índice de Gini computado con esta información es menor respecto al que es posible calcular con ingresos individuales. Otra diferencia entre las estimaciones de desigualdad utilizando ambas fuentes de datos radica en el hecho de que la misma no cae de manera constante durante la década del 2000 utilizando intensidades de luces. Como fuera mencionado anteriormente, la principal explicación detrás de esto se encuentra en la caída en los valores de intensidades de luces agregadas para Argentina durante los años de crisis 2008-2009.

Los resultados asociados a las estimaciones de índices de Gini teniendo en cuenta los aglomerados representados en la EPH y utilizando una definición de urbanidad más inclusiva pueden encontrarse en la tabla A2 (apéndice A) y figuras 6 y 7.

A partir de los resultados presentados, queda claro que la desigualdad en intensidad de luces medida a partir del índice de Gini es menor para aglomerados urbanos incluidos en la EPH respecto a su análogo teniendo en cuenta centros urbanos adicionales durante toda la serie. Si bien durante la década de 1990 esta diferencia en niveles se mantuvo relativamente constante, dando indicios de que la desigualdad medida de esta manera se incrementó a ritmos similares para ambos grupos de aglomerados, no ocurrió lo mismo en el primer decenio del nuevo siglo. En particular, durante los años 2000, el índice de Gini que considera solo áreas geográficas pertenecientes a aglomerados urbanos identificados en la EPH experimentó una caída mayor respecto a su análogo que incluye más centros urbanos. 
Figura 6. Índice de Gini Total Urbano

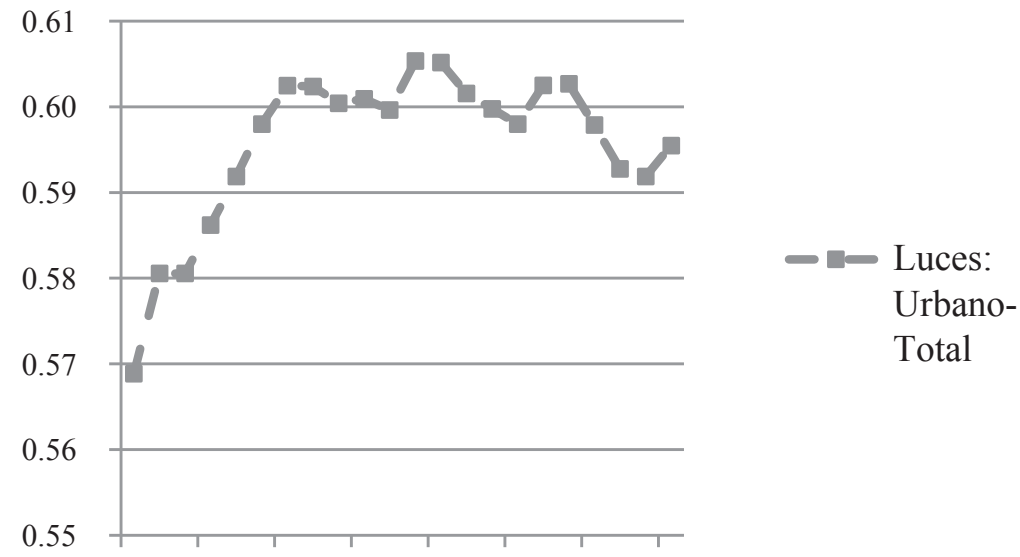

19921995199820012004200720102013

Fuente: elaboración propia sobre la base de NOAA y CIESIN.

En consecuencia, es posible pensar que la recuperación económica ocurrida a comienzos del presente siglo en el país benefició en mayor medida, en términos de una mayor igualdad, a aglomerados urbanos incluidos en las encuestas de hogares argentinas respecto a centros urbanos no incluidos en las mismas.

Tomando como referencia la dinámica de la desigualdad de ingresos medida por el índice de Gini sobre el ingreso per cápita familiar utilizando información proveniente de la EPH a partir de la metodología SEDLAC (2020), es posible observar en la figura 6 cómo el índice de Gini computado sobre intensidad de luces posee tendencias similares al mismo medido por ingresos, aunque con variaciones más pequeñas. El coeficiente de correlación entre las estimaciones de desigualdad usando ambas fuentes de información es de alrededor de 68\%, incrementándose a un $88 \%$ cuando no se consideran años cercanos a la crisis de 2008-2009. Como fuera mencionado anteriormente, al comparar el índice de Gini mediante ingreso per cápita familiar respecto a aquel computado a partir de intensidad de luces, se están contrastando medidas de desigualdad individuales o familiares versus espaciales. Teniendo en cuenta este punto, un posible ejercicio de comparación entre ambas series radica en evaluar índices de desigualdad a partir de valores promedio de los aglomerados urbanos disponibles en la EPH de manera de utilizar la misma unidad de análisis. Tal como se representa en la figura 6.1, existe una correlación de 
$72 \%$ entre los índices de Gini a nivel aglomerado utilizando promedios de ingreso per cápita familiar e intensidad de luces, a pesar de que ambas medidas comienzan a diferir en los últimos años. Al igual que en la sección IV en la que se computó la tasa de pobreza por intensidad de luces, este resultado sugiere que las estimaciones de desigualdad a partir de información satelital no logran captar en igual cuantía el fuerte descenso en la desigualdad de ingresos reportado en la EPH. Las razones para que esto ocurra son similares a las esbozadas en la sección IV: el incremento en la relevancia de la seguridad social representó un elemento importante a la hora de explicar la caída en la desigualdad de ingresos, el cual no es capturado tan directamente por datos de microáreas geográficas pero si por datos de ingresos individuales. Estas transferencias monetarias no están estrechamente asociadas a la actividad, sino que justamente representan un mecanismo tendiente a otorgarle mayor seguridad a los ingresos de la población más vulnerable.

Figura 6.1. Índice de Gini por intensidad de luces para Urbano-EPH y por ingresos

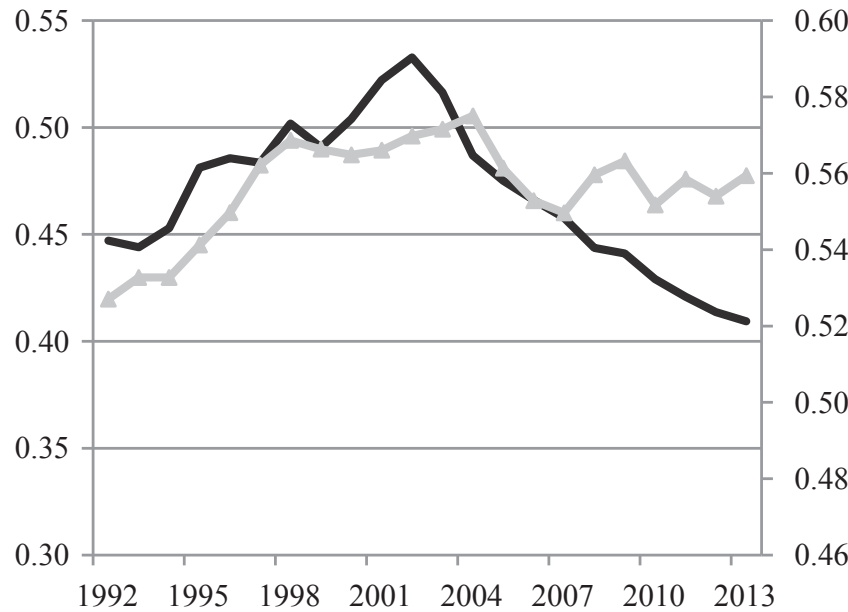

Ingresos: EPH (eje izq.)

-Luces:

UrbanoEPH (eje der.)

Fuente: elaboración propia sobre la base de NOAA, CIESIN y SEDLAC (CEDLAS y Banco Mundial).

Por otro lado, el análisis de desigualdad presentado es extendido mediante el cómputo de Curvas de Incidencia del Crecimiento (CIC) para diferentes períodos entre los años 1992 y 2013. Las mismas capturan gráficamente el crecimiento anualizado de la intensidad de luces para cada decil de la distribución entre dos momentos en el tiempo. 
Figura 7. Índices de Gini a nivel aglomerado por ingreso per cápita familiar e intensidad de luces
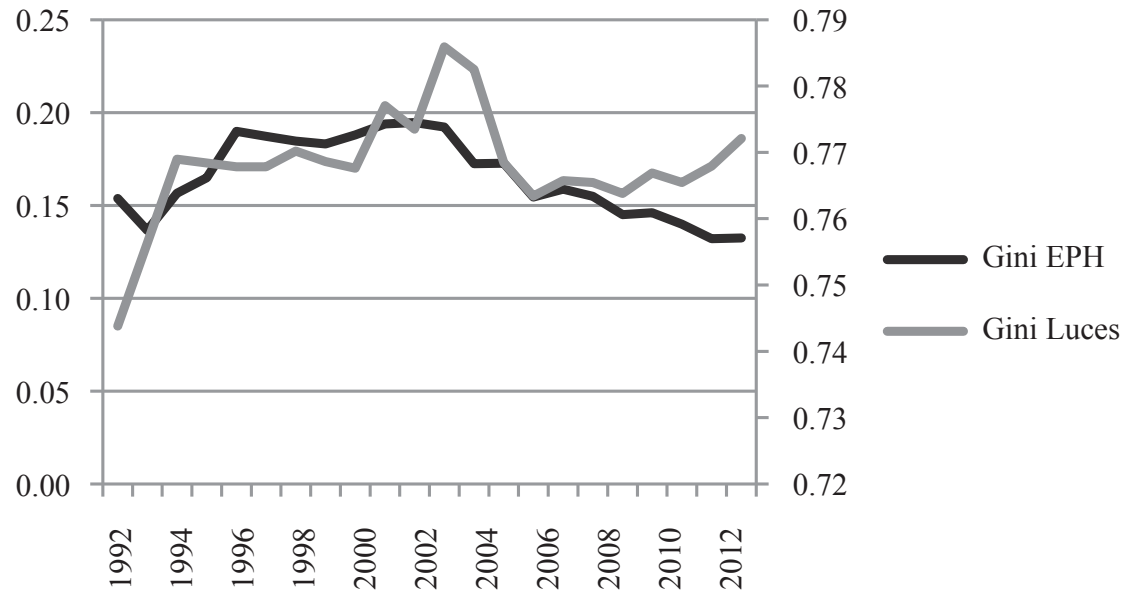

Fuente: elaboración propia sobre la base de NOAA, CIESIN y SEDLAC (CEDLAS y Banco Mundial).

De esta manera, períodos en los que la pendiente la curva de incidencia del crecimiento es positiva (negativa) dan evidencia de un mayor (menor) crecimiento en intensidad de luces en deciles altos de la distribución respecto a los deciles más bajos, lo que implica que el crecimiento en intensidad de luces en dicho período fue desigualador (igualador). Como fuera mencionado en la sección II, es posible seguir la evolución de cada píxel en términos de intensidad de luces y población a lo largo de todo el período bajo análisis. En consecuencia, para construir las curvas de incidencia del crecimiento de intensidad de luces, primero se calculan los deciles de la distribución de intensidad de luces en el año inicial y se identifican los píxeles dentro de cada decil. Luego, se computa el crecimiento anualizado en términos de intensidad de luces para dichos deciles ${ }^{10}$. Los resultados asociados a las CIC para la población urbana de Argentina pueden encontrarse en la figura 8.

10 Es esperable que el crecimiento anual de la intensidad de luces del decil 10 esté subestimado debido al límite superior que posee dicha variable. 
Figura 8. Curvas de Incidencia del Crecimiento para población urbana
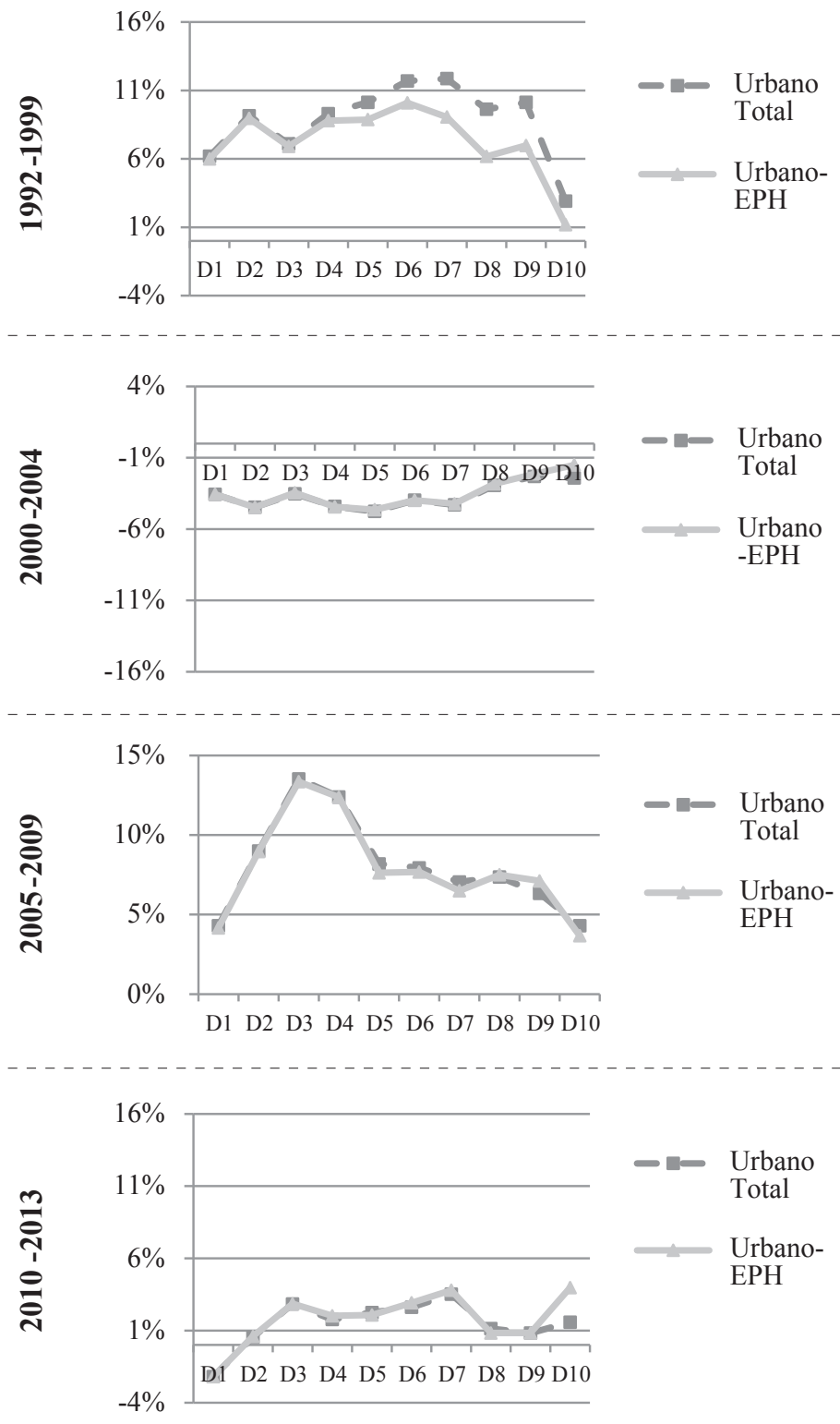

Fuente: elaboración propia sobre la base de NOAA y CIESIN. 
Las CIC presentadas dan cuenta de un incremento en la desigualdad medida por intensidad de luces en la década de $1990^{11}$. Sin embargo, solo para el total de aglomerados urbanos se evidencia una pendiente positiva en la CIC, sugiriendo que el fenómeno desigualador en núcleos urbanos no incluidos en la EPH fue más fuerte respecto al ocurrido solo en aglomerados representados en dicha encuesta de hogar, cuya pendiente no posee un signo claro. Luego, durante el período de crisis comprendido entre los años 2000 y 2005, es posible observar cómo todos los deciles de la distribución de intensidad de luces perdieron valor para ambos conjuntos de aglomerados. Este resultado es consistente con la pérdida de ingresos general de la población producto de la recesión. No obstante, esa pérdida fue más marcada para los deciles más bajos sugiriendo un incremento en la desigualdad durante ese lapso. En los cinco años siguientes de recuperación económica, además de mostrar una recuperación en los ingresos aproximados de todos los deciles de la distribución de luminosidad, las CIC muestran una pendiente negativa dando cuenta de una disminución de la desigualdad por intensidad de luces con evoluciones similares entre urbano total y aglomerados de la EPH. Si bien durante ese lapso de tiempo la intensidad de luces para los primeros deciles de la distribución se incrementó más que para deciles mayores a la mediana, el bajo crecimiento del primer decil es capaz de explicar, al menos en parte, por qué las estimaciones de pobreza y desigualdad no sufrieron una caída muy fuerte en dicho período. Por último, en los últimos años bajo análisis es posible ver cómo las CIC poseen una pendiente prácticamente nula dando cuenta de un estancamiento en la caída de la desigualdad evidenciada en el lustro anterior, cualquiera sea la definición de urbanidad utilizada. Adicionalmente, todos los deciles de la distribución de intensidad de luces muestran un incremento menor que en el período anterior dando cuenta de cierta desaceleración en la actividad económica.

\section{CONCLUSIONES}

El análisis de la pobreza y la desigualdad representan una de las temáticas más relevantes concernientes al desempeño socioeconómico de los países. La correcta medición de dichos fenómenos es crucial para conocer las condiciones de vida de los habitantes de una nación o región. Es por estas razones que se realizan especiales esfuerzos para lograr ese cometido. Las fuentes de información tradicionales, representadas por encuestas de hogares, son sumamente útiles para conocer

11 La pendiente de la Curva de Incidencia del Crecimiento resulta positiva si no consideramos al último decil de la distribución de intensidad de luces que, como se dijo anteriormente, presenta un acotamiento en su variación. 
la evolución de estas variables sociales. Sin embargo, las mismas no son perfectas. Esto último motiva la búsqueda de datos alternativos a partir de los cuales sea posible estimar los indicadores sociales más tradicionales para conocer en qué sentido son capaces de agregar conocimiento al respecto. En este sentido, la utilización de información de tipo satelital respecto a la intensidad de luces emanada al espacio exterior por la actividad humana es capaz de brindar información adicional a la provista por encuestas de hogares.

En este trabajo, se han utilizado imágenes satelitales con el objetivo construir una variable que aproxime el ingreso per cápita promedio para pequeñas áreas geográficas y luego realizar un análisis sobre las dinámicas de la pobreza y la desigualdad sobre dicha variable para Argentina. El caso argentino es de singular importancia debido a que, en la actualidad, la Encuesta Permanente de Hogares (EPH) reporta información solo para 31 aglomerados urbanos de más de 100000 habitantes y solo es posible estimar una serie comparable para 10 de ellos desde el año 1992.

Naturalmente, la utilización de información de tipo satelital implica que el análisis distributivo toma un perfil espacial a pesar del importante nivel de desagregación que permiten las imágenes satelitales. Los resultados obtenidos sugieren que los indicadores sociales computados a partir de imágenes satelitales siguen patrones similares a aquellos obtenidos a partir del procesamiento de la EPH en Argentina. A su vez, la variabilidad de dichos indicadores resulta naturalmente menor en el primer caso debido a la característica espacial de los datos. Por último, tanto los indicadores de pobreza como de desigualdad utilizando imágenes satelitales no captan una caída continua durante los años 2000 debido a que los valores de intensidad de luces agregadas presentan una caída significativa para los años de crisis de 2008-2009. 


\section{APÉNDICE A}

Figura A1. Intensidad de luces y ajuste por costo eléctrico

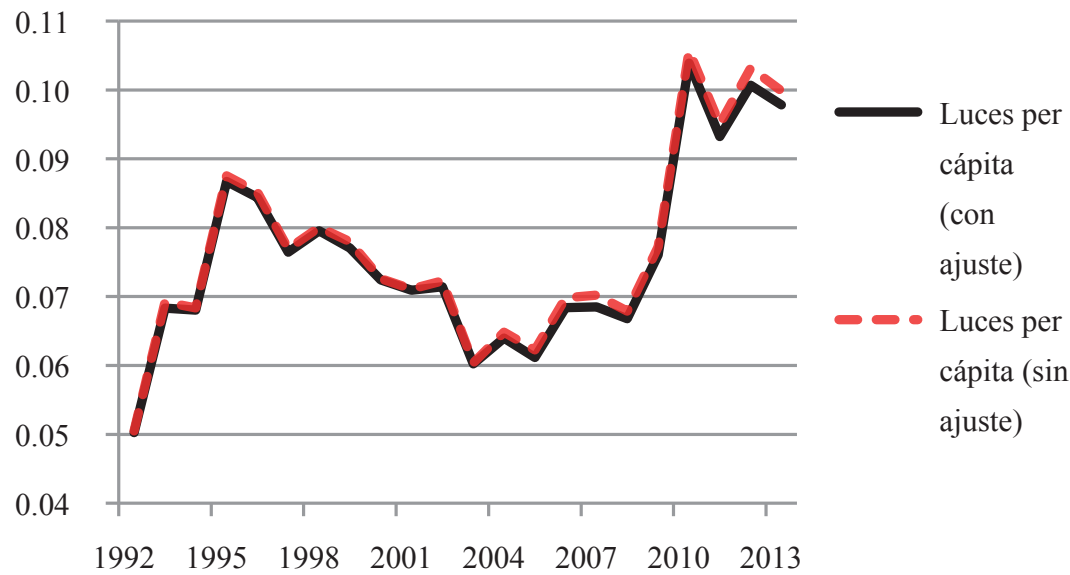

Fuente: elaboración propia sobre la base de NOAA y CIESIN.

Figura A2. Diferencia en intensidad de luces con y sin ajuste por costo eléctrico

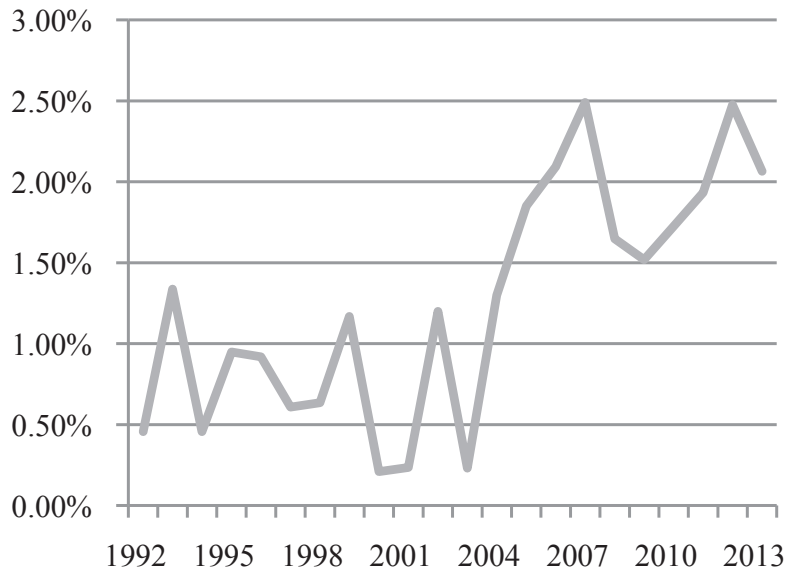

Diferencia sin ajuste vs. con ajuste (\%)

Fuente: elaboración propia sobre la base de NOAA y CIESIN. 


\section{APÉNDICE B}

Tabla B1. Tasas de pobreza por intensidad de luces

\begin{tabular}{|c|c|c|c|}
\hline \multicolumn{4}{|c|}{ Tasas de pobreza } \\
\hline Año & Nacional & Urbana-Total & Urbana-EPH \\
\hline 1992 & $29.27 \%$ & $22.15 \%$ & $13.13 \%$ \\
\hline 1993 & $30.06 \%$ & $22.98 \%$ & $13.98 \%$ \\
\hline 1994 & $30.85 \%$ & $23.81 \%$ & $14.83 \%$ \\
\hline 1995 & $30.21 \%$ & $22.97 \%$ & $13.60 \%$ \\
\hline 1996 & $29.58 \%$ & $22.13 \%$ & $12.37 \%$ \\
\hline 1997 & $31.83 \%$ & $24.02 \%$ & $12.93 \%$ \\
\hline 1998 & $34.99 \%$ & $27.04 \%$ & $14.74 \%$ \\
\hline 1999 & $37.05 \%$ & $29.12 \%$ & $16.17 \%$ \\
\hline 2000 & $39.11 \%$ & $31.20 \%$ & $17.60 \%$ \\
\hline 2001 & $39.89 \%$ & $31.93 \%$ & $18.44 \%$ \\
\hline 2002 & $39.39 \%$ & $31.38 \%$ & $17.87 \%$ \\
\hline 2003 & $40.61 \%$ & $32.70 \%$ & $19.08 \%$ \\
\hline 2004 & $39.03 \%$ & $31.05 \%$ & $17.67 \%$ \\
\hline 2005 & $38.21 \%$ & $30.34 \%$ & $16.97 \%$ \\
\hline 2006 & $38.13 \%$ & $30.30 \%$ & $16.89 \%$ \\
\hline 2007 & $38.05 \%$ & $30.34 \%$ & $17.05 \%$ \\
\hline 2008 & $38.84 \%$ & $30.96 \%$ & $17.47 \%$ \\
\hline 2009 & $38.61 \%$ & $30.83 \%$ & $17.65 \%$ \\
\hline 2010 & $36.56 \%$ & $28.88 \%$ & $16.11 \%$ \\
\hline 2011 & $36.55 \%$ & $28.85 \%$ & $16.02 \%$ \\
\hline 2012 & $36.54 \%$ & $28.90 \%$ & $16.04 \%$ \\
\hline 2013 & $37.04 \%$ & $29.39 \%$ & $16.41 \%$ \\
\hline
\end{tabular}

Fuente: elaboración propia sobre la base de NOAA y CIESIN. 
Tabla B2. Índices de Gini urbanos

\begin{tabular}{|c|c|c|}
\hline \multicolumn{3}{|c|}{ Índices de Gini } \\
\hline Año & Urbano-Total & Urbano-EPH \\
\hline 1992 & 0.569 & 0.527 \\
\hline 1993 & 0.581 & 0.533 \\
\hline 1994 & 0.581 & 0.533 \\
\hline 1995 & 0.586 & 0.541 \\
\hline 1996 & 0.592 & 0.550 \\
\hline 1997 & 0.598 & 0.562 \\
\hline 1998 & 0.602 & 0.569 \\
\hline 1999 & 0.602 & 0.566 \\
\hline 2000 & 0.600 & 0.565 \\
\hline 2001 & 0.601 & 0.566 \\
\hline 2002 & 0.600 & 0.570 \\
\hline 2003 & 0.605 & 0.572 \\
\hline 2004 & 0.605 & 0.575 \\
\hline 2005 & 0.602 & 0.561 \\
\hline 2006 & 0.600 & 0.553 \\
\hline 2007 & 0.598 & 0.550 \\
\hline 2008 & 0.602 & 0.560 \\
\hline 2009 & 0.603 & 0.563 \\
\hline 2010 & 0.598 & 0.552 \\
\hline 2011 & 0.593 & 0.558 \\
\hline 2012 & 0.592 & 0.554 \\
\hline 2013 & 0.595 & 0.559 \\
\hline
\end{tabular}

Fuente: elaboración propia sobre la base de NOAA y CIESIN. 
Figura B3. Pobreza por intensidad de luces. Solo luces positivas

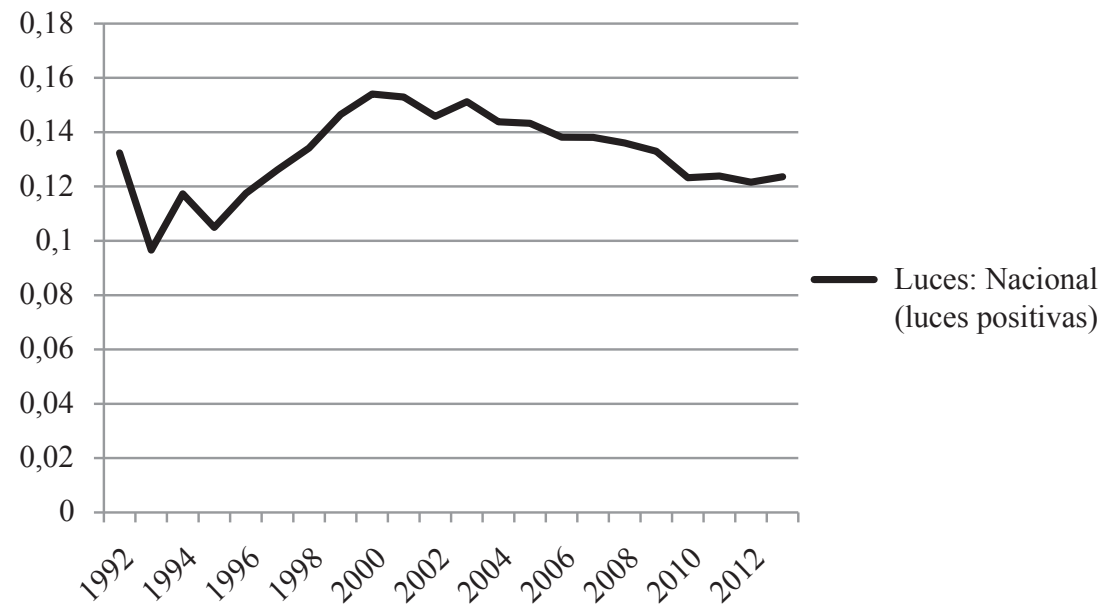

Fuente: elaboración propia sobre la base de NOAA y CIESIN.

\section{REFERENCIAS BIBLIOGRÁFICAS}

Chen, X., \& Nordhaus, W. (2011). Using luminosity data as a proxy for economic statistics. PNAS U.S.A. 108(21), 8589-8594. Recuperado de https://doi. org/10.1073/pnas.1017031108

Elvidge, C., Sutton, P., Ghosh, T, Tuttle, B., Baugh, K., Bhaduri, B., \& Bright, E. (2009). A global poverty map derived from satellite data. Computers \& Geosciences 35(8), 16521660. Recuperado de https://doi.org/10.1016/j. cageo.2009.01.009

Engstrom, R., Hersh, J., \& Newhouse, D. (2017). Poverty from space: using highresolution satellite imagery for estimating economic well-being. (World Bank Policy Research Working Paper No. 8284). Recuperado de https://openknowledge.worldbank.org/handle/10986/29075

Garganta, S. (2019). Midiendo el efecto distributivo de la asignación universal por hijo en Argentina: efecto directo, indirecto y potenciales mejoras. Económica, 65, 17-68. Recuperado de https://doi.org/10.24215/18521649e008

Hancevic, P., \& Navajas, F. (2015). Consumo residencial de electricidad y eficiencia energética. Un enfoque de regresión cuantílica. El trimestre económico, 82(328), 897-927. Recuperado de http://www.scielo.org.mx/pdf/ete/ v82n328/2448-718X-ete-82-328-00897.pdf 
Henderson, J., Storeygard, A., \& Weil, D. (2012). Measuring economic growth from outer space. American Economic Review, 102(2), 994-1028. doi: 10.1257/ aer.102.2.994

Hodler, R., \& Raschky, P. (2014) Regional Favoritism. The Quarterly Journal of Economics, 129(1), 995-1033. Recuperado de https://doi.org/10.1093/qje/qju004

Jean, N., Burke, M., Xie, M., Matthew Davies, W., Lobell, D., \& Ermon, S. (2016). Combining satellite imagery and machine learning to predict poverty. Science (353)6301, 790-794. doi: 10.1126/science.aaf7894

Ibañez Martín, M. M., Guzowski, C., \& Maidana, F. (2020). Pobreza energética y exclusión en Argentina: mercados rurales dispersos y el programa PERMER. Revista Reflexiones, 99(1). doi: 10.15517/rr.v99i1.35971

Michalopoulos, S., \& Papaioannou, E. (2013). Pre-colonial ethnic institutions and contemporary African development. Econometrica, 81(1), 113-152. Recuperado de https://doi.org/10.3982/ECTA9613

Mveyange, A. (2015). Night lights and regional income inequality in Africa. (WIDER Working Paper Series No. 085). doi: 10.35188/UNU-WIDER/2015/974-9

Noor, A., Alegana, V., Gething, P., Tatem, A., \& Snow, R. (2008). Using remotely sensed night-time light as a proxy for poverty in Africa. Population Health Metrics, 6(1), 5. Recuperado de doi: 10.1186/1478-7954-6-5

Pinkovskiy, M., \& Sala-i-Martin, X. (2016). Lights, Camera ... Income! Illuminating the National Accounts-Household Surveys Debate. The Quarterly Journal of Economics, 131(2), 579631. Recuperado de https://doi.org/10.1093/qje/qjw003

SEDLAC (2020). Socioeconomic database for Latin America and the Caribbean. CEDLAS and The World Bank. Recuperado de https://www.cedlas.econo. unlp.edu.ar/wp/en/estadisticas/sedlac/metodologia-sedlac/

Smith, B., \& Wills, S. (2018). Left in the dark? oil and rural poverty. Journal of the Association of Environmental and Resource Economists, 5(4), 865-904. Recuperado de https://www.journals.uchicago.edu/doi/abs/10.1086/698512

Sutton, P., Elvidge C., \& Ghosh, T. (2007). Estimation of gross domestic product at sub-national scales using nighttime satellite imagery. International Journal of Ecological Economics \& Statistics 8(SO7), 5-21. Recuperado de https:// www.researchgate.net/profile/Ghosh_Tilottama/publication/242254394_ Estimation_of_Gross_Domestic_Product_at_Sub-National_Scales_ Using_Nighttime_Satellite_Imagery/links/00b49532130d0ea7d1000000/ Estimation-of-Gross-Domestic-Product-at-Sub-National-Scales-UsingNighttime-Satellite-Imagery.pdf

Tornarolli, L. (2018). Series comparables de indigencia y pobreza: Una propuesta metodológica. (CEDLAS Documento de Trabajo, No. 226), Recuperado de https://www.cedlas.econo.unlp.edu.ar/wp/wp-content/uploads/doc_cedlas226.pdf 
Tornarolli, L., Ciaschi, M., \& Galeano, L. (2018). Income distribution in latin america: The evolution in the last 20 years: A global approach. (CEDLAS Documento de Trabajo No. 234) Recuperado de https://www.cedlas.econo.unlp. edu.ar/wp/wp-content/uploads/doc_cedlas234.pdf

Wang, W., Cheng, H., \& Zhang, L. (2012). Poverty assessment using DMSP/OLS night-time light satellite imagery at a provincial scale in China. Advances in Space Research, 49(8), 1253-1264. Recuperado de https://doi.org/10.1016/j. asr.2012.01.025

(C) 2021 por los autores; licencia no exclusiva otorgada a la revista Estudios económicos. Este artículo es de acceso abierto y distribuido bajo los términos y condiciones de una licencia Atribución-No Comercial 4.0 Internacional (CC BY-NC 4.0) de Creative Commons. Para ver una copia de esta licencia, visite http://creativecommons.org/licenses/by-nc/4.0 